\title{
Baetens, Romans à contrainte
}

\section{Elisa Bricco}

\section{(2) OpenEdition \\ Journals}

\section{Edizione digitale}

URL: http://journals.openedition.org/studifrancesi/30807

DOI: 10.4000/studifrancesi.30807

ISSN: 2421-5856

\section{Editore}

Rosenberg \& Sellier

\section{Edizione cartacea}

Data di pubblicazione: 1 avril 2006

Paginazione: 193

ISSN: 0039-2944

\section{Notizia bibliografica digitale}

Elisa Bricco, «Baetens, Romans à contrainte», Studi Francesi [Online], 148 (XLX | I) | 2006, online dal 30 novembre 2015, consultato il 19 avril 2021. URL: http://journals.openedition.org/studifrancesi/30807 ; DOI: https://doi.org/10.4000/studifrancesi.30807

Questo documento è stato generato automaticamente il 19 avril 2021.

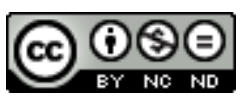

Studi Francesi è distribuita con Licenza Creative Commons Attribuzione - Non commerciale - Non opere derivate 4.0 Internazionale. 


\title{
Baetens, Romans à contrainte
}

\author{
Elisa Bricco
}

\section{NOTIZIA}

BAETENS, Romans à contrainte, Amsterdam-New-York, Rodopi (Faux titre), 2005, pp. 190.

1 Il volume si propone di stabilire una nuova teoria della "contrainte" attraverso la lettura di alcuni romanzi contemporanei, che dimostrano quanto questa forma di scrittura sia ormai appannaggio anche della prosa e non solo della poesia, come si riteneva tradizionalmente. Inoltre il libro si pone come ideale continuazione di un discorso sulla "contrainte" in poesia che l'A. aveva pubblicato nel 1995, L'éthique de la contrainte. Seconda parte di un dittico, dunque, e ulteriore problematizzazione delle categorie della "contrainte", attraverso l'analisi di meccanismi narrativi che non si usa considerare "contrainte", ma che in determinati contesti lo diventano.

2 Nel capitolo introduttivo: Plaidoyer pour une littérature à contraintes, l'A. si lancia in una discussione, molto convincente, sul valore della scelta della "contrainte" e sulla ricchezza dei testi che ne derivano. Il progetto di scrittura "à contrainte" è intimamente legato ai testi prodotti, e il valore letterario di essi non può assolutamente essere distinto dal fatto di essere generati da quella precisa costrizione, iniziale e fondatrice. In quei testi la forma e il contenuto sono inseparabili dalla presenza della "contrainte" e l'A. arriva a affermare che proprio in virtù della scelta iniziale i testi acquisiscono valore: la "contrainte" spinge alla ricerca di una scrittura scevra di facilità e in un certo senso 'impegnata'.

3 Nei quattro capitoli che seguono l'A. analizza alcuni esempi emblematici di "contrainte" in prosa: la scrittura "sous influence" di Jean-Benoit Puech; il "discours analogique" di Jean Paulhan, Claude Ollier e José Lezama Lima; le diverse "contraintes" che sono state alla base di alcune opere, non le più evidentemente 'costrette', del Nouveau Roman, tra le quali Le Libera di Pinget, i testi di Jean Lahougue e di Raymond Federman; infine, l'A. si occupa di "prose prosaïque" che distingue dalla "prose narrative", e specificatamente di autori che alternano le due tipologie di scrittura 
privando completamente il lettore di punti di riferimento riconoscibili. Il volume termina con una riflessione sull'utilizzo della "contrainte" da parte di due scrittori contemporanei molto diversi, Renaud Camus e Jacques Roubaud, i quali attraverso le loro sperimentazioni sondano le possibili posizioni del soggetto nella scrittura. Un soggetto che si trasforma quasi in un non-soggetto, tanto la sua trasformazione si fa radicale. 